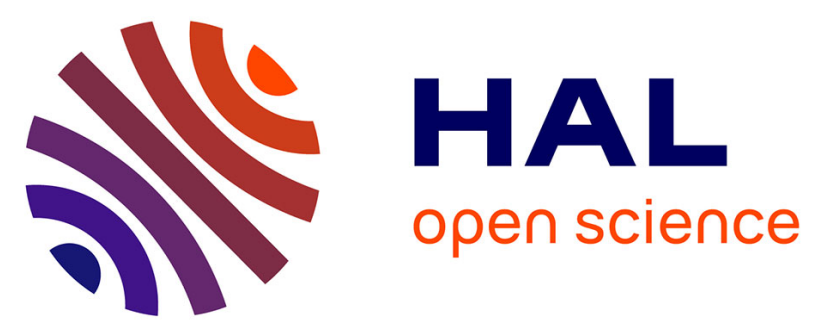

\title{
The influence of early-life allocation to antlers on male performance during adulthood: Evidence from contrasted populations of a large herbivore
}

Jean-François Lemaître Lemaître, Louise Cheynel, Frédéric Douhard, Gilles Bourgoin, François Débias, Hubert Ferté, Emmanuelle Gilot-Fromont, Sylvia Pardonnet, Maryline Pellerin, Benjamin Rey, et al.

\section{To cite this version:}

Jean-François Lemaître Lemaître, Louise Cheynel, Frédéric Douhard, Gilles Bourgoin, François Débias, et al.. The influence of early-life allocation to antlers on male performance during adulthood: Evidence from contrasted populations of a large herbivore. Journal of Animal Ecology, 2018, Linking organismal functions, life history strategies and population performance, 87 (4), pp.921-932. 10.1111/1365-2656.12833 . hal-02391690

\section{HAL Id: hal-02391690 https://hal.science/hal-02391690}

Submitted on 13 Jul 2021

HAL is a multi-disciplinary open access archive for the deposit and dissemination of scientific research documents, whether they are published or not. The documents may come from teaching and research institutions in France or abroad, or from public or private research centers.
L'archive ouverte pluridisciplinaire HAL, est destinée au dépôt et à la diffusion de documents scientifiques de niveau recherche, publiés ou non, émanant des établissements d'enseignement et de recherche français ou étrangers, des laboratoires publics ou privés. 


\title{
The influence of early-life allocation to antlers on male performance during adulthood: Evidence from contrasted populations of a large herbivore
}

\author{
Jean-François Lemaître ${ }^{1}$ (D) | Louise Cheynel ${ }^{1}$ (D) | Frédéric Douhard ${ }^{1,2}$ | \\ Gilles Bourgoin $^{1,3}$ | François Débias ${ }^{1}$ | Hubert Ferté ${ }^{4}$ | Emmanuelle Gilot-Fromont ${ }^{1,3}$ | \\ Sylvia Pardonnet ${ }^{1}$ | Maryline Pellerin ${ }^{5}$ | Benjamin Rey ${ }^{1}$ | Cécile Vanpé ${ }^{1,6}$ |
}

\section{A. J. Mark Hewison ${ }^{7}$ | Jean-Michel Gaillard ${ }^{1}$}

${ }^{1}$ Laboratoire de Biométrie et Biologie Evolutive UMR5558, Univ Lyon, Université Lyon 1, CNRS, Villeurbanne, France; ${ }^{2}$ GenPhySE, Université de Toulouse, INRA, INPT, INP-ENVT, Castanet Tolosan, France; ${ }^{3}$ VetAgro Sup, Université de Lyon, Marcy-l'Etoile, France; ${ }^{4}$ EA 4688 "VECPAR," UFR Pharmacie, Université de Reims Champagne-Ardenne, Reims, France; ${ }^{5}$ Office National de la Chasse et de la Faune Sauvage, Unité Cervidés-Sanglier, Bar-le-Duc, France; ${ }^{6}$ Office National de la Chasse et de la Faune Sauvage, Unité Prédateurs - Animaux déprédateurs, Villeneuve de Rivière, France and ${ }^{7} \mathrm{CEFS}$, Université de Toulouse, INRA, Castanet-Tolosan, France

Correspondence

Jean-François Lemaître

Email: jean-francois.lemaitre@univ-lyon1.fr

Funding information

ANR AGEX, Grant/Award Number: ANR-15 CE32-0002-01; LABEX ECOFECT, Grant/ Award Number: ANR-11-LABX-0048; ANR11-IDEX-0007; French National Research

Agency (ANR)
Abstract

1. To secure mating opportunities, males often develop and maintain conspicuous traits that are involved in intrasexual and/or intersexual competition. While current models of sexual selection rely on the assumption that producing such traits is costly, quantifying the cost of allocating to secondary sexual traits remains challenging.

2. According to the principle of allocation, high energy allocation to growth or sexual traits in males should lead to reduced energy allocation to the maintenance of cellular and physiological functions, potentially causing them to age faster, with impaired survival.

3. We evaluated the short-term and delayed consequences of energy allocation to antlers early in life in two contrasted populations of roe deer, Capreolus capreolus. Although most males mate successfully for the first time in their fourth year, antlers are grown annually from the first year of life onwards. We tested the prediction that a high level of allocation to antler growth during the first two years of life should lead to lower body mass, antler size and survival during the early and late prime stages, as well as to reduced longevity overall.

4. Growing and carrying long antlers during the first years of life was not associated with any detectable cost in the late prime stage. The positive association between antler growth in early life and adult body mass instead supports that fawn antler acts as an honest signal of phenotypic quality in roe deer.

5. For a given body mass, yearling males growing longer antlers displayed impaired performance during their late prime. We also found a trend for a short-term survival cost of allocation to relative antler length during the second year of life. 
6. Yearling males that grow long antlers relative to their mass might display a fast lifehistory tactic. We argue that differential allocation to secondary sexual traits generates a diversity of individual trajectories that should impact population dynamics.

\section{KEYWORDS}

ageing, Capreolus capreolus, life history, roe deer, secondary sexual traits, senescence

\section{1 | INTRODUCTION}

The evolution of complex secondary sexual traits in males is generally explained by the positive relationship between the intensity of their expression and breeding success (Andersson, 1994), as is the case for plumage coloration in many birds (Brommer, Ahola, \& Karstinen, 2005). All models of sexual selection that have been developed thus far (Kuijper, Pen, \& Weissing, 2012) share the common and mandatory assumption that growing and maintaining secondary sexual traits is costly (Kotiaho, 2001), although these costs may vary in relation to individual condition (Rowe \& Houle, 1996). However, measuring the fitness costs of bearing extravagant sexual traits empirically is challenging and most studies of life-history (e.g. higher mortality due to higher predation risk) or physiological (e.g. lower performance of the immune system) costs to date have reported contrasting patterns (Kotiaho, 2001). A meta-analysis across birds, spiders, insects and fish revealed that the expression of secondary sexual traits is strongly condition-dependent as the expression of a given sexual trait (known to predict mating success) is generally positively associated with longevity (Jennions, Møller, \& Petrie, 2001). However, while males in good condition during the early stages of life are able to develop the most conspicuous sexual traits, they may suffer from a higher degree of somatic deterioration compared to males that are in low condition during early life, which can lead to an accelerated rate of ageing (Adler, Telford, \& Bonduriansky, 2016). In line with these results, it has recently been argued that the costly nature of secondary sexual traits should be rooted in the theories currently proposed to explain the evolution of ageing (Hooper, Lethonen, Schwanz, \& Bonduriansky, 2018; Tidière et al., 2015).

Our understanding of the ageing process takes its root in the principle of allocation (Cody, 1966), a cornerstone of life-history theory (Stearns, 1992). This principle states that individuals need to share a finite pool of resources among competing functions such as growth, reproduction and survival. When it concerns a long-lasting or delayed cost of a given allocation, this principle is closely related to the disposable soma theory of ageing (Kirkwood \& Holliday, 1979). This theory postulates that individuals that allocate a substantial amount of resources to reproduction will have less resources to devote to the set of molecular mechanisms (e.g. DNA repair mechanisms) involved in somatic maintenance (Kirkwood \& Rose, 1991). Therefore, individuals that allocate much to reproduction early in life will accumulate a variety of damages that will ultimately cause a shortened life span or an increased rate of reproductive senescence (Lemaître \& Gaillard,
2017). The central role played by early- vs. late-life trade-offs in the evolution of ageing constitutes the core of the life-history theory of ageing (Kirkwood, 2017) and has been supported by many empirical studies (Hammers, Richardson, Burke, \& Komdeur, 2013; Jankowiak, Zyskowski, \& Wysocki, 2018). However, most of these studies have focused on females (Lemaître et al., 2015) and there is no consensus yet on whether early- vs. late-life trade-offs are prevalent in males. During the reproductive season, males devote a substantial part of their resources to sexual competition (Andersson, 1994). While sexual competition can take different forms, male breeding success is determined by allocation to secondary sexual traits in most species (Bonduriansky, 2007; Emlen, 2008).

Several studies have revealed that the allocation to secondary sexual traits can be associated with diverse physiological costs (Garratt \& Brooks, 2012). In the Australian painted dragon (Ctenophorus pictus), males that maintained a high level of head coloration suffered from a rapid rate of telomere loss (Giraudeau et al., 2016). This finding suggests that males with particularly conspicuous traits might have impaired fitness later in life. While current theories predict that males should suffer from long-term or delayed costs of growing costly sexual traits, such allocation can levy immediate fitness costs. Thus, successful reproduction often has shortterm reproduction and survival costs in male birds (Bleu, Gamelon, \& Saether, 2016), which might potentially be driven by strong allocation to sexual traits.

Overall, measuring costs of allocation to secondary sexual traits during early life is important because the expression of secondary sexual traits varies over the lifetime (Lemaître \& Gaillard, 2017), and also because allocation to secondary sexual traits early in life increases the absolute level of allocation to the entire growth process, which potentially leads to detrimental fitness consequences later in life (Lee, Monaghan, \& Metcalfe, 2013; Metcalfe \& Monaghan, 2003). This avenue of research should boost our understanding of the relationships linking individual development with population dynamics.

So far, the few studies that assessed the long-term fitness consequences of early allocation to secondary sexual traits in mammalian males have mostly been performed on bovids (see Table 1 for a review), and showed that the intensity of early horn growth is rarely associated with a delayed survival cost (Table 1). While the horns of bovids grow continuously over most of their lifetime, the amount of energy allocated to the annual horn growth is quite limited. On the contrary, male cervids grow antlers that are cast 


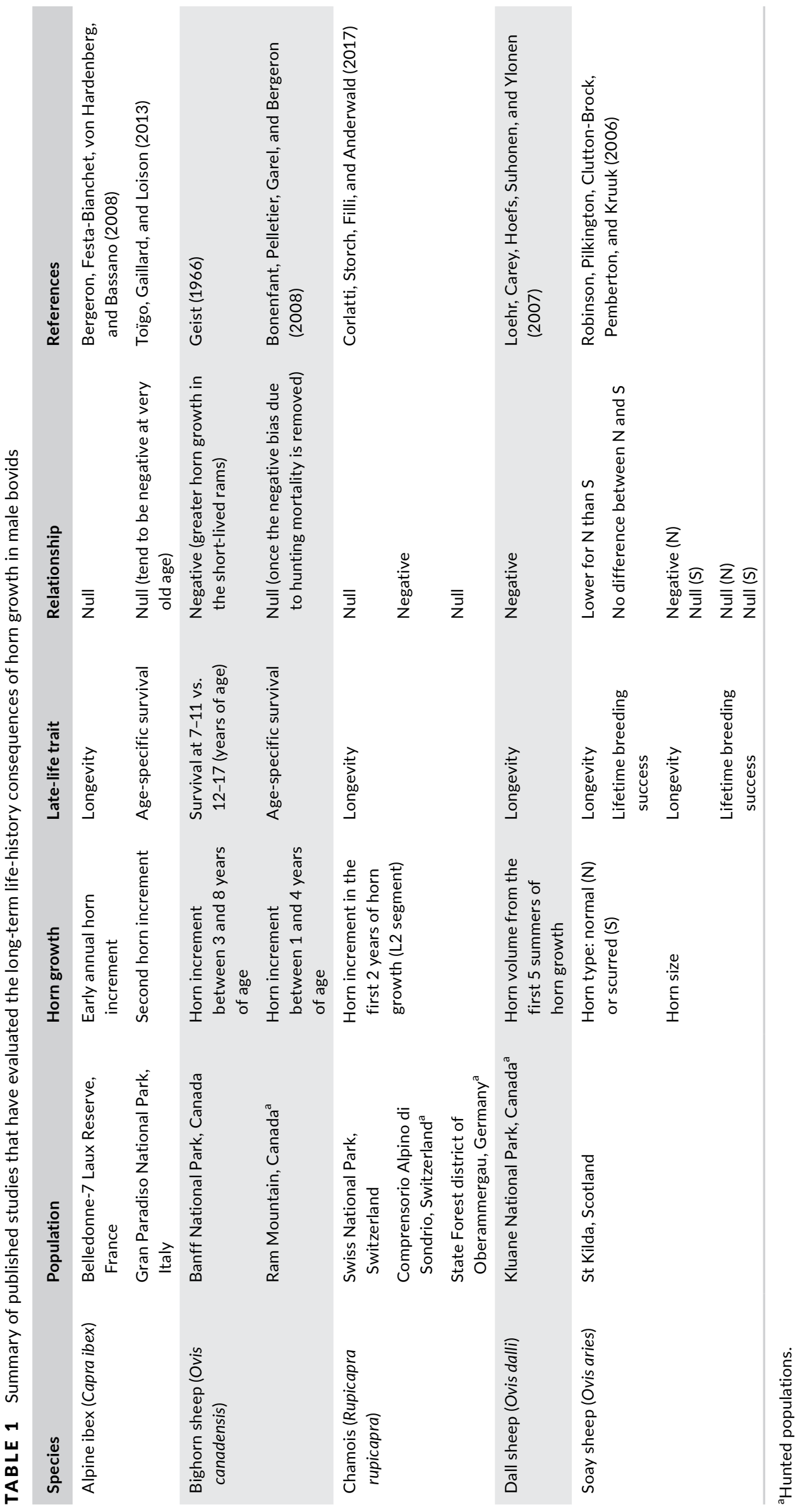


and fully regrown every year (Chapman, 1975). This repeatedly high annual allocation of resources to antler growth is thus expected to be particularly costly. So far, the only study that quantified delayed costs of growing antlers reported that male red deer (Cervus elaphus) that allocated substantially to antler growth between 4 and 9 years of age did not suffer any detrimental consequences on harem size or antler length later on (Lemaître, Gaillard, Pemberton, Clutton-Brock, \& Nussey, 2014). However, young males grow antlers from their first year of life, well before they can successfully mate and at a time when they must allocate intensively to body growth (Douhard, Gaillard, Pellerin, Jacob, \& Lemaître, 2017). Furthermore, delayed fitness costs of early allocation to antler growth might impact survival at the end of the prime-aged adulthood (i.e. when the onset of actuarial senescence occurs; Gaillard, Garratt, \& Lemaître, 2017) rather than reproductive success (Lemaître \& Gaillard, 2017). Surprisingly, the long-term fitness consequences of early development of secondary sexual traits have not yet been investigated. Moreover, while there is increasing evidence that early-life environmental conditions mediate trade-offs between early- and late-life performance (Balbontín \& Møller, 2015), whether the interplay between environmental conditions and the expression of secondary sexual traits early in life shapes the magnitude of delayed fitness costs remains unknown.

We propose to fill this knowledge gap by investigating the consequences of allocation to antlers in early life (defined here as the first two years of life) on survival, body mass and antler size during adulthood in two populations of European roe deer (Capreolus capreolus) living in contrasted habitats. In this slightly polygynous mammal, males are territorial from early spring until mid-July-late August and generally begin mating during their fourth year, although some males can sire offspring in their third year of life (Vanpé et al., 2009). Male roe deer systematically grow antlers each year from their first year of life onwards. Growing large antlers in early life well before mating opportunities occur should thus come at a cost in terms of survival, body mass or antler growth later in life. Finally, as resource availability mediates the trade-off between growth and somatic maintenance, such costs should be more pronounced in populations experiencing poor environmental conditions.

\section{2 | MATERIALS AND METHODS}

\section{1 | Study population}

We studied the populations of roe deer at Trois-Fontaines (TF) and Chizé $(\mathrm{CH})$ living in enclosed forests. Trois-Fontaines (1,360 ha), located in north-eastern France $\left(48^{\circ} 43^{\prime} \mathrm{N}, 4^{\circ} 55^{\prime} \mathrm{E}\right)$, has a continental climate characterized by moderately severe winters and warm rainy summers. This site has rich soils and provides high-quality habitat for roe deer (Pettorelli et al., 2006). In contrast, in Chizé (2,614 ha), located in western France $\left(46^{\circ} 50^{\prime} \mathrm{N}, 0^{\circ} 25^{\prime} \mathrm{W}\right)$, the climate is temperate oceanic with Mediterranean influences. This forest has low productivity due to poor-quality soils and frequent summer droughts
(Pettorelli et al., 2006) and thereby provides a quite poor habitat for roe deer in most years.

Roe deer have been intensively monitored using a long-term capture-mark-recapture programme since 1975 and 1977 for TroisFontaines and Chizé, respectively. Every year and for each site, 10-12 days of capture is organized between December and March (Gaillard et al., 1993a). Once an individual is captured, its sex and body mass (to the nearest $50 \mathrm{~g}$ ) are recorded and a basic clinical examination is performed.

\subsection{Allocation to antler growth during the first two years of life}

Antlers grow each year from the end of November until early March (i.e. before the velvet is shed). Roe deer are in hard antler until the end of October/early November when they cast their antlers (Sempéré \& Boissin, 1981). During their first year of life, males develop a small "button" (i.e. a very short antler with a round top instead of a spike) on top of their pedicle before growing their first full antlers at 1 year of age (Figure 1). Then, males generally develop a four-point (in yearlings) or five-/six-point (in adults) head. Antler length was measured to the nearest $0.5 \mathrm{~cm}$ along the external side of the main beam, from the base of the antler to the top of the main beam (Vanpé et al., 2007). Antler length was used as a proxy for allocation to antler growth because there is a strong covariation among the different antler traits in deer (Lemaître et al., 2014). When an individual was caught more than once in a given year, only the last measure was considered. When both antlers were intact, the average length was computed and retained for the analyses. When one antler was broken, the value of the remaining intact antler was retained. When both antlers were broken, the individual was removed from the dataset. Although a few captures occurred in October-November in the very first years of monitoring, we restricted our analyses to data collected from 1 December to avoid possible overlap between antlers growing during the current year and uncast antlers from the previous year. All males included in our analyses were of known age because they were caught within their first year of life, when age can

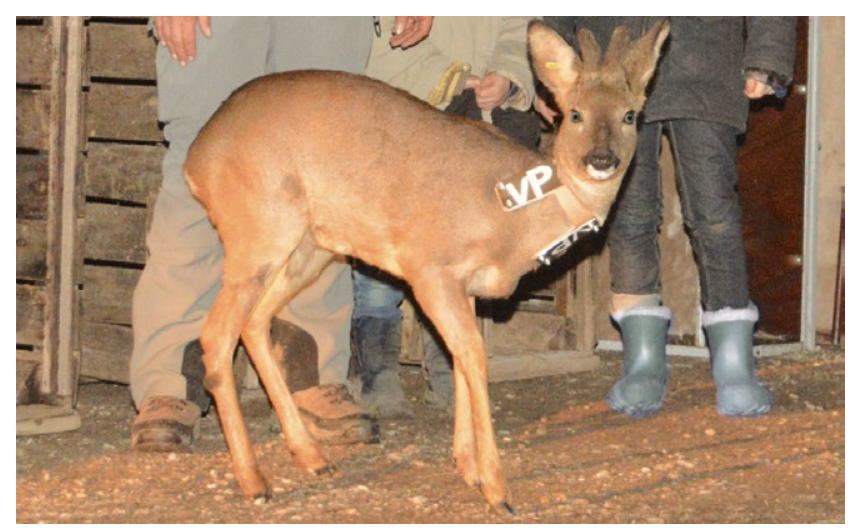

FIGURE 1 A fawn with visible buttons (photograph reproduced with permission from F. Débias) 
be assigned without error from tooth eruption and wear patterns (Hewison et al., 1999).

In roe deer, the antler growth cycle is governed by complex interactions between the photoperiod and the endogenous rhythm of the hypothalamic-pituitary-gonadal axis (Sempéré \& Lacroix, 1982). Therefore, for a given cohort, the date of capture provides a better predictor of antler size during antler growth than birth date (Vanpé et al., 2007). We analysed the relationship between antler length and the Julian date of capture (with 1 December as day 0). As antler growth is a nonlinear process (Goss, 1983), we fitted different functions to assess reliably the shape of the relationship between antler length (log-transformed) and date of capture in fawns (i.e. 8 months of age) and yearlings (i.e. 20 months of age): constant (i.e. no change in antler length with date of capture), linear, a threshold function (i.e. piecewise linear function) with one slope (i.e. antler length increasing linearly with date of capture until reaching a plateau at a given date) and a threshold function with two slopes (i.e. antler length increasing linearly with date of capture until a given date and then increasing further, but with a different slope). To estimate these threshold values, the deviance profile of the models including the slopes was used and the date of capture providing the lowest deviance was selected as the threshold value (UIm \& Cox, 1989). Model selection was based on the Akaike Information Criterion (AIC). We calculated AIC weights ( $\mathrm{AICW}$ ) to assess the relative likelihood that a given model was the best among all the fitted models (Burnham \& Anderson, 2002). We selected the model with the lowest AIC except when the difference in AIC $(\triangle \mathrm{AIC})$ between two competing models was $<2$, in which case we retained the simplest model. Once the model that best captured the shape of the relationship was identified, we looked for potential differences between populations by including "population" as a fixed factor, either as an additive effect or in interaction with the Julian date.

As previously observed (Vanpé et al., 2007), the linear model best represented variation in antler length (log-transformed) with date of capture in fawns (Table S1; Figure 2a; slope of $0.022 \pm 0.002$, $N=224$ ). Fawn antler length did not differ between populations ( $\triangle \mathrm{AIC}$ of +1.93 for the model including "population"), and the daily growth rate did not differ between populations ( $\triangle \mathrm{AIC}$ of +3.57 for the model including the "population $\times$ date of capture" interaction term). We computed a standardized fawn antler length from the selected model by adjusting antler length to the median date of capture (i.e. 8 February) and pooling the data for both populations. The best model accounting for variation in yearling antler length in relation to capture date was the threshold model with a single slope (Table S2). Antler length increased linearly with date of capture until day 59 (i.e. 28 January) (Figure 2 b; slope of $0.024 \pm 0.002$, $N=257$ ) and remained constant thereafter. Antler length did not differ between populations ( $\triangle \mathrm{AIC}$ of +1.81 for the model including "population"), but the threshold date did ( $\triangle \mathrm{AIC}$ of -5.17 for the model including the "population $x$ date of capture" interaction term). In both populations, antler length increased linearly with the date of capture $(0.032 \pm 0.004, N=100$, and $0.021 \pm 0.002$, $N=157$ at Trois-Fontaines and Chizé, respectively), but the threshold date was earlier at Chizé (day 46 corresponding to 16 January; Figure 2d) than at Trois-Fontaines (day 72 corresponding to 11 February; Figure 2c), which matches the longer day length at Chizé than at Trois-Fontaines in January-February. We then computed a standardized yearling antler length by adjusting antler length to the median date of capture (i.e. 8 February) using the model selected for each population.
FIGURE 2 Relationship between antler length (log-transformed) during the first two years of life and Julian date of capture. Fawn antler length (at 8 months of age) for males at Chizé and Trois-Fontaines (a); yearling antler length (at 20 months of age) at Chizé and TroisFontaines (b); yearling antler length (at 20 months of age) at Trois-Fontaines (c); and yearling antler length (at 20 months of age) at Chizé (d)
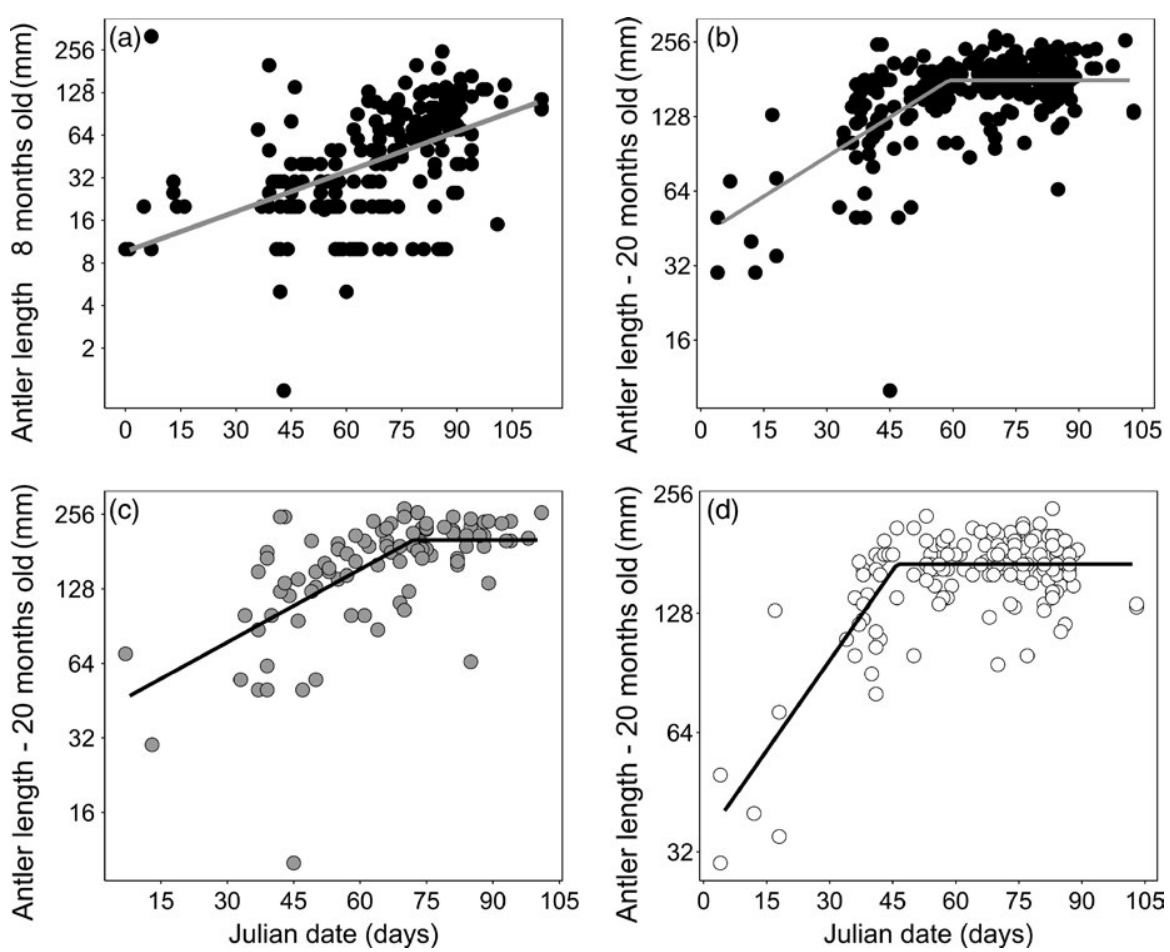

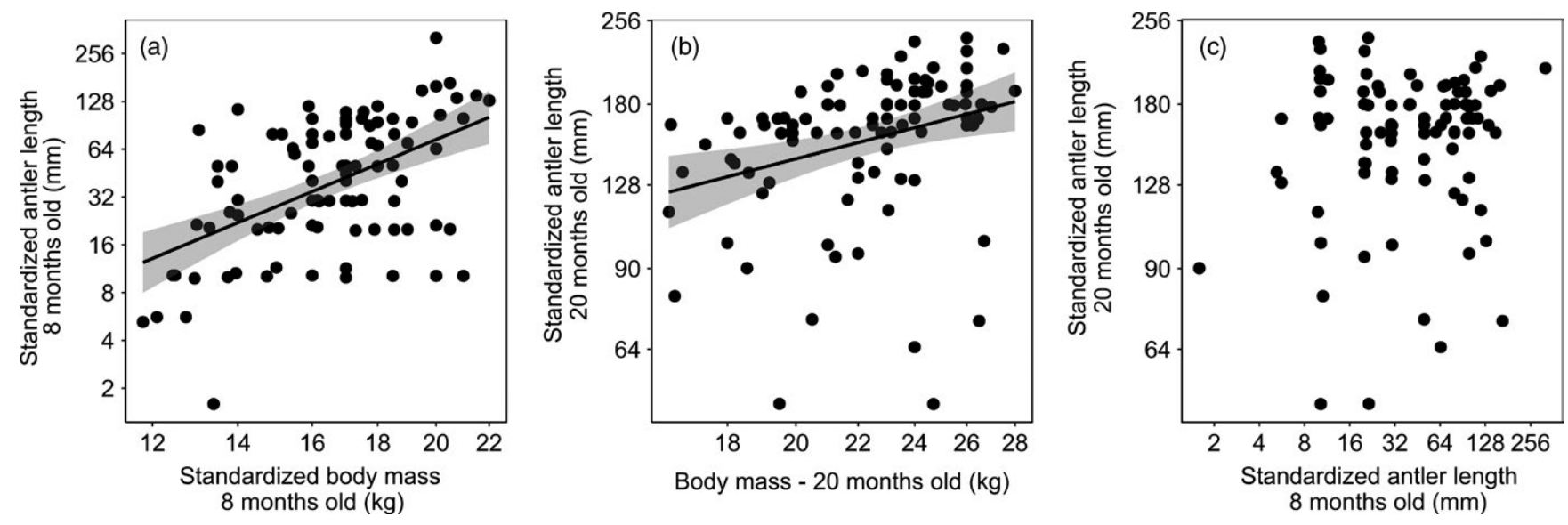

FIGURE 3 Relationship between fawn standardized antler length (log-transformed, measured at 8 months of age) and fawn standardized body mass (log-transformed) (a). Relationship between yearling standardized antler length (log-transformed, measured at 20 months of age) and yearling body mass (log-transformed, measured at 20 months of age) (b). Relationship between yearling standardized antler length (log-transformed and measured at 20 months of age) and fawn standardized antler (log-transformed, measured at 8 months of age)

We analysed the relationship between body mass (logtransformed) and date of capture during the first year of life. In roe deer, fawns consistently gain mass during their first year of life (Hewison, Gaillard, Angibault, Van Laere, \& Vincent, 2002) and the date of capture explains a substantial part of the observed variation in body mass during the first winter (Douhard et al., 2017). In contrast, although the exact date of birth was unknown for most individuals, we expect such a factor to be negligible because roe deer births are highly synchronized (80\% of births occur within a range of 20 days; Gaillard, Delorme, Julien, \& Tatin, 1993b). As expected, we found that body mass increased with date of capture (slope of $0.0011 \pm 0.0004, N=224$; Figure S1). To analyse the possible longterm effect of allocation to fawn relative antler length (see statistical analysis), we thus standardized body mass by the Julian date (8 February), as done previously (Vanpé et al., 2007). We followed the same procedure for yearling antler length. As expected, there was no detectable variation in body mass in relation to date at this age (Figure S2; slope of $0.0003 \pm 0.0005, N=257$ ), and the yearling body mass was thus not corrected for date of capture.

\section{3 | Covariation between fawn and yearling antler length}

We used two metrics to describe the level of allocation to antler growth during early life: fawn and yearling absolute standardized antler length. As we expected heavier males to allocate more resources to antler growth in absolute terms than lighter males (Vanpé et al., 2007), we measured the effect of relative allocation to antlers during the first two years of life by adding body mass (i.e. fawn body mass standardized for the date of capture or yearling non-standardized body mass) as a covariate in the corresponding set of models (see below).

Yearling antler size could potentially be influenced by the allocation to antlers the year before, and we thus first tested whether fawn and yearling antler length could be considered as independent.
As the physiological pathway governing antler growth is the same across all ages (Sempéré \& Lacroix, 1982), we expected a positive relationship to occur between absolute antler length during the first and second years of life, and we thus tested for a positive correlation between allocation to fawn and yearling antler growth using a linear regression. We replicated the analyses on relative (to body mass) measures of antler length. To do this, we did not include fawn and yearling body mass (log-transformed) to avoid multicollinearity issues. We thus first computed fawn relative antler length as the residuals from the linear regression between absolute standardized antler length and fawn standardized body mass (slope of $1.98 \pm 0.37, N=224$; Figure 3a). We followed the same procedure to compute yearling relative antler length (slope of $0.68 \pm 0.17, N=257$; Figure $3 b)$. We then computed yearling relative antler length as the residuals from this linear regression between yearling relative antler length and body mass. Both fawn and yearling antler length were measured on 93 males (76 in Chizé and 17 in Trois-Fontaines).

Measures of fawn and yearling antler length were independent (absolute metrics: slope of $0.043 \pm 0.033$; Figure $3 c$, Table S3; relative metrics: slope of $0.001 \pm 0.04$; Table S4).

\subsection{Early and late prime-age adulthood traits}

To assess the consequences of male allocation to antler growth during early life on performance during early and late prime-age adulthood, we used three survival metrics: the probability of reaching 3 years of age (survival metric for short-term survival), the probability of reaching 6 years of age (survival metric for long-term survival) and longevity. We also used two phenotypic traits that are positively associated with fitness in roe deer: adult body mass (Gaillard, Festa-Bianchet, Delorme, \& Jorgenson, 2000) and adult antler length (Vanpé, Gaillard, Kjellander, Delorme, \& Hewison, 2010). For a given male, adult body mass and antler length were measured as the median values of measures recorded between 4 and 6 years of age (body mass) and 4 and 8 years of 
age (antler length), as these traits subsequently show senescence (Douhard et al., 2017; Vanpé et al., 2007). Longevity (from 1.5 to 14 years) was measured as the exact number of years an individual lived, including only those individuals that were intensively monitored by observations and that died from natural causes (i.e. individuals that were removed from the population for translocation or that died from human-related incidents such as car collisions and capture-related mortality were right-censored).

\subsection{Analysis of the consequences of strong allocation to antlers during early life}

We investigated potential trade-offs between allocation to antlers during early life and both condition and survival during adulthood and possible between-population differences in these trade-offs. For each combination of late-prime trait (dependent variable) and absolute antler length in early life, a set of competing models was fitted (e.g. Table S5a). When testing the possible long-term deleterious consequences of allocation to relative antler length early in life, body mass (i.e. fawn standardized body mass or yearling nonstandardized body mass) was added as a covariate in all models of the set. All models included the cohort (year of birth) fitted as a random effect (32 cohorts between 1975 and 2006). When analysing adult antler length, we also included adult body mass as a covariate (e.g. Table S5b) to measure the consequences of early allocation to antler growth on both absolute and relative adult antler length. For analysis of longevity, adult body mass and adult antler length, we fitted linear mixed-effects models ("Imer" function in the R package LME4, Bates, Mächler, Bolker, \& Walker, 2015). For survival beyond 3 and 6 years of age, we used generalized linear mixed-effects models with survival entered as a binomial variable. We tested the short-term survival costs (i.e. survival beyond 3 years of age) only for yearling antler length as our sample size was too limited to investigate short-term survival costs in fawns. All traits except survival were log-transformed. For each set of analyses, we used AIC for model selection (see above for a full description of the procedure). All analyses were performed using

TA B LE 2 Sample sizes used per analysis. Samples sizes in brackets are population-specific (Chizé; Trois-Fontaines)

\begin{tabular}{|c|c|c|}
\hline \multirow[b]{2}{*}{ Dependent variables } & \multicolumn{2}{|c|}{ Independent variables } \\
\hline & $\begin{array}{l}\text { Fawn antler } \\
\text { length }\end{array}$ & $\begin{array}{l}\text { Yearling } \\
\text { antler length }\end{array}$ \\
\hline Longevity & $137(94 ; 43)$ & $180(101 ; 79)$ \\
\hline $\begin{array}{l}\text { Survival beyond } 6 \text { years of } \\
\text { age }\end{array}$ & $137(94 ; 43)$ & $190(105 ; 85)$ \\
\hline $\begin{array}{l}\text { Survival beyond } 2 \text { years of } \\
\text { age }\end{array}$ & & $190(105 ; 85)$ \\
\hline Adult body mass & $121(98 ; 23)$ & $126(78 ; 48)$ \\
\hline Adult antler length & $111(89 ; 22)$ & $110(70 ; 40)$ \\
\hline Antler length (20 months) & $93(76 ; 17)$ & \\
\hline
\end{tabular}

R version 3.4.0 (R Core Team, 2015), and all results are reported as $M \pm S E$.

In our dataset, two individuals had particularly short antlers for their age (one fawn with antlers measuring $1 \mathrm{~mm}$ and one yearling with antlers measuring $10 \mathrm{~mm}$ ). All analyses were performed with and without these males, and in most cases, results were qualitatively similar (Table S5 vs. Table S6 for fawn antler length; Table S7 vs. Table S8 for yearling antler length). As we did not have any biological reason to exclude these males, we decided to present the results obtained with the complete dataset. We explicitly specified in the text when including these outliers mattered. Population-specific sample sizes used for each analysis are provided in Table 2 .

\section{3 | RESULTS}

\section{1 | Late prime-age adulthood consequences of allocation to fawn antler growth}

Absolute and relative antler length were not associated with longevity or survival beyond 6 years of age (longevity: slope of $0.04 \pm 0.05$ and slope of $0.05 \pm 0.06$; survival: slope of $0.07 \pm 0.20$ and slope of $-0.71 \pm 0.47$ for absolute and relative antler length, respectively). In all cases, the constant model was selected (Table S5a and S5b). However, when analysing the effect of absolute antler length on longevity, the selected model contained population as a fixed factor. For a median value of antler length, males lived about one year longer at Chizé than at Trois-Fontaines (Trois-Fontaines: 4.49 years 95\% Cl [3.78-5.33], $N=43$; Chizé: 5.39 years 95\% Cl [4.80-6.05], $N=94$, estimates averaging all cohorts). The selected model of variation in adult body mass included additive effects of absolute antler length (slope of $0.022 \pm 0.08, N=121$ ) and population (Table S5a,

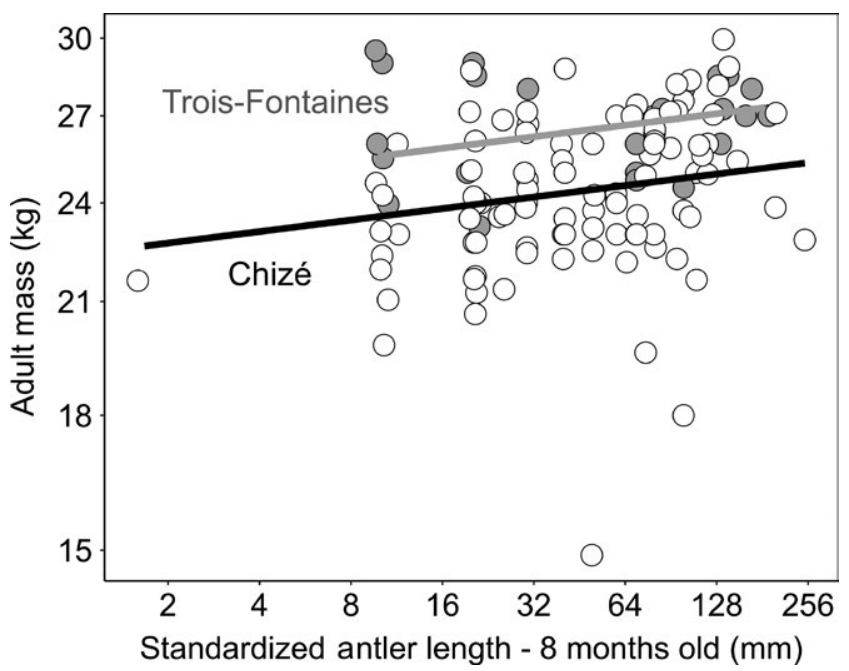

FIGURE 4 Relationship between adult body mass (logtransformed) and fawn absolute antler length (log-transformed and measured at 8 months of age). Chizé: dark line, open circle; Trois-Fontaines: grey line, grey points. The relationship and data are represented on a double logarithmic scale 
Figure 4). For a median antler size, males were about $10 \%$ heavier at Trois-Fontaines than at Chizé $(26.65 \mathrm{~kg}, 95 \% \mathrm{Cl}$ [25.59-27.76], $\mathrm{N}=23$ vs. $24.36 \mathrm{~kg}, 95 \% \mathrm{Cl}$ [23.89-24.85], $\mathrm{N}=98$, estimates averaging all cohorts). In the equivalent set of models for relative antler length (Table S5b), the selected model only included a positive effect of body mass (slope of $0.39 \pm 0.06$; Figure S3). The selected model for adult antler length only included a positive effect of adult body mass (slope of $0.61 \pm 0.22, N=111$ ), as expected for this allometric relationship (Figure $\mathrm{S4}$ ).

\subsection{Early and late prime-age adulthood consequences of yearling allocation to antler growth}

No relationship occurred between allocation to absolute antler length and the probability of reaching 3 years of age (slope of $-0.56 \pm 0.48$; Table S7a). On the other hand, yearling tended to suffer from carrying long antlers for their body mass (slope of $-0.90 \pm 0.55$ ), even if the most parsimonious model included body mass only (Table S7b). Heavy individuals survived better (slope of $2.63 \pm 1.29$ ). Increasing by $1 \mathrm{~kg}$ the average body mass was associated with an increased survival of $2.5 \%$.

Allocation to absolute antler length was not associated with any longevity or long-term survival cost in either roe deer population (slopes of $-0.13 \pm 0.11$ and of $-0.29 \pm 0.35$ for longevity and survival beyond six years, respectively; see Table S7a and S7b). Analyses of relative antler length suggested that antler length for a given mass was negatively associated with longevity (Table 3 , Figure 5). Increasing the average antler size by $5 \mathrm{~cm}$ at a given mass led to a reduction in longevity by $4.84 \%$. However, most models performed equally well (Table S7b). For survival beyond six years, the selected model included body mass and an interaction between population and antler length (Table S7b). At Chizé, a strong relative allocation to antler growth led to a decrease in the probability of surviving beyond six years of age (Table 4, Figure 6), while no relationship occurred at Trois-Fontaines (Table 4, Figure 5c,d). When the individual with $10-\mathrm{mm}$ antlers was removed from the analysis, a negative effect of relative antler length was detected across both populations (Table S8b). Increasing the average relative antler size by $1 \mathrm{~cm}$ led survival to be reduced by $2.4 \%$. Both absolute and relative antler length were independent of adult body mass (slope of $0.03 \pm 0.02$ and slope of $-0.02 \pm 0.01$ for absolute and relative antler length, respectively; Table S7a and S7b). The selected model for absolute antler length only included population. Males were heavier at Trois-Fontaines than at Chizé, independently of antler

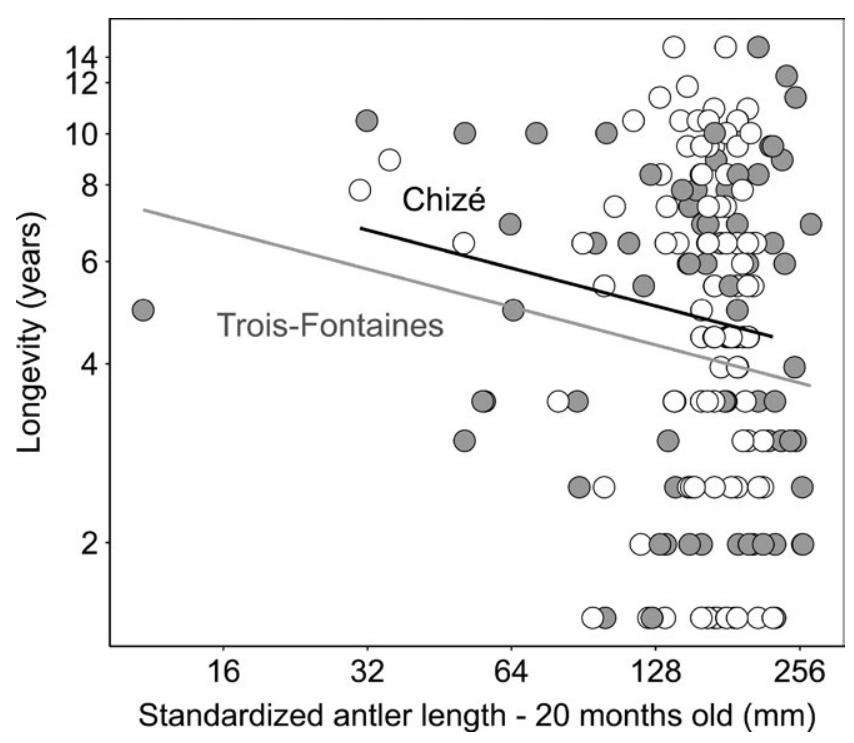

FIGURE 5 Relationship between the longevity and yearling relative antler length (at 20 months of age) for Chizé (dark line, open circle) and Trois-Fontaines (grey line, grey points). The relationship and data are represented on a double logarithmic scale

growth. The selected model for relative antler revealed that body mass was positively associated with adult body mass (slope of $0.62 \pm 0.05, N=126$ ). Finally, for adult antler length, the selected model contained both standardized antler length and body mass, revealing that relative antler length is positively associated with long antlers during adulthood (slope of $0.18 \pm 0.08$; Table S7a and s7b).

\section{4 | DISCUSSION}

Contrary to our predictions, we did not detect any evidence of delayed costs of allocation to antler growth during the first year of life in two roe deer populations living in highly different ecological contexts. Fawns with the longest (absolute or relative) antlers also had the highest body mass as adults, suggesting that the length of the first antlers reliably indicates individual performance during adulthood. This interpretation is supported by our finding that fawn antler length (but also yearling) was also positively associated with body mass, which indicates that antler length is a condition-dependent trait (Vanpé et al., 2007). In yearling, the growth of long absolute antlers has no influence on future male performance. However, for

\begin{tabular}{|lllc|} 
& Estimates & SE & $t$ \\
\hline Intercept & -0.56 & 1.20 & -0.47 \\
\hline Population & -0.15 & 0.10 & -1.51 \\
\hline Yearling body mass & 1.03 & 0.40 & $2.64^{* *}$ \\
\hline Standardized yearling antler length & -0.21 & 0.11 & -1.87 \\
\hline
\end{tabular}

TABLE 3 Parameter estimates from the model of variation in longevity as a function of relative allocation to antlers in yearlings (see Table S7b). Chizé is used as the reference population

${ }^{* *} p<.01$. 
TAB LE 4 Parameter estimates from the selected models of variation in the probability of surviving beyond six years of age (on a logit scale) as a function of relative allocation to antlers in yearlings (see Table S7b). Chizé is used as the reference population

\begin{tabular}{lclc} 
& Estimates & SE & $t$ \\
\hline Intercept & 0.24 & 5.29 & 0.046 \\
\hline $\begin{array}{l}\text { Population } \\
\text { Standardized } \\
\text { yearling antler } \\
\text { length }\end{array}$ & -11.06 & 5.20 & $-2.13^{*}$ \\
\hline $\begin{array}{l}\text { Yearling body mass } \\
\text { Standardized } \\
\text { yearling antler } \\
\text { length } \times \text { Population }\end{array}$ & -2.19 & 0.94 & $-2.33^{*}$ \\
\hline
\end{tabular}

${ }^{*} p<.05 ;{ }^{* *} p<.01$.

a given body mass, yearlings with long antlers tend to be show a reduced longevity. The cost of growing large relative antlers as yearling was stronger on the probability of reaching 6 years of age, especially for males living in the poorest habitat (Chizé).

Although the exact physiological mechanisms regulating the full antler growth cycle are still debated (Bartos, Bubenik, \& Kuzmova, 2012; Price \& Allen, 2004), experimental manipulation of antler size has revealed that the annual growth and casting of antlers is governed by a complex interaction between photoperiod and several hormones, especially insulin-like growth factor 1 (IGF-1) and testosterone (Price \& Allen, 2004). While the relative contribution of these hormones to antler size is difficult to decipher (Ditchkoff, Spicer, Masters, \& Lochmiller, 2001), positive correlations between levels of testosterone and IGF-1 and antler length have been repeatedly reported (Bartos et al., 2012), notably in roe deer (Schams, Barth, Heinze-Mutz, Pflaum, \& Karg, 1992; Sempéré \& Boissin, 1981). An increasing number of studies have highlighted the potential deleterious effects of these hormones (Foo, Nakagawa, Rhodes, \& Simmons, 2017), which are assumed to play a pivotal role in governing life-history trade-offs (Dantzer \& Swanson, 2012), notably between allocation to sexual competition during early life and ageing (Brooks \& Garratt, 2017). As yearlings with the longest relative antler length also carry long antlers as adults, repeated exposure to high hormonal levels might lead to reduced survival. The relationship between yearling and adult antler size suggests that yearlings with disproportionally large antlers will also have high competitive abilities over their entire life. Roe deer males are strongly territorial from early spring (March-April) to late August-early September (Andersen, Duncan, \& Linnell, 1998), so that the costs of territory defence are likely higher than the costs associated with antler growth. Our results suggest that these costs might be higher when environmental conditions are poor, although the low sample size at Trois-Fontaines prevents to draw any firm conclusion. Overall, yearling males that grow long antlers for their mass might play a fast life-history tactic, involving the repeated defence of large territories, but impaired survival. Short antlers in yearlings should delay territoriality establishment (Vanpé et al., 2009), and thereby age at first mating. Delayed age at first
FIGURE 6 Relationship between the probability of surviving beyond 6 years of age and yearling relative antler length (at 20 months of age) in Chizé (a, b) and Trois-Fontaines (c, d). Points (of different size according to the sample size) indicate the average survival probabilities within each class of yearling relative antler length, or body mass. In both cases, the interval between two successive classes corresponds to an increment of 5\%
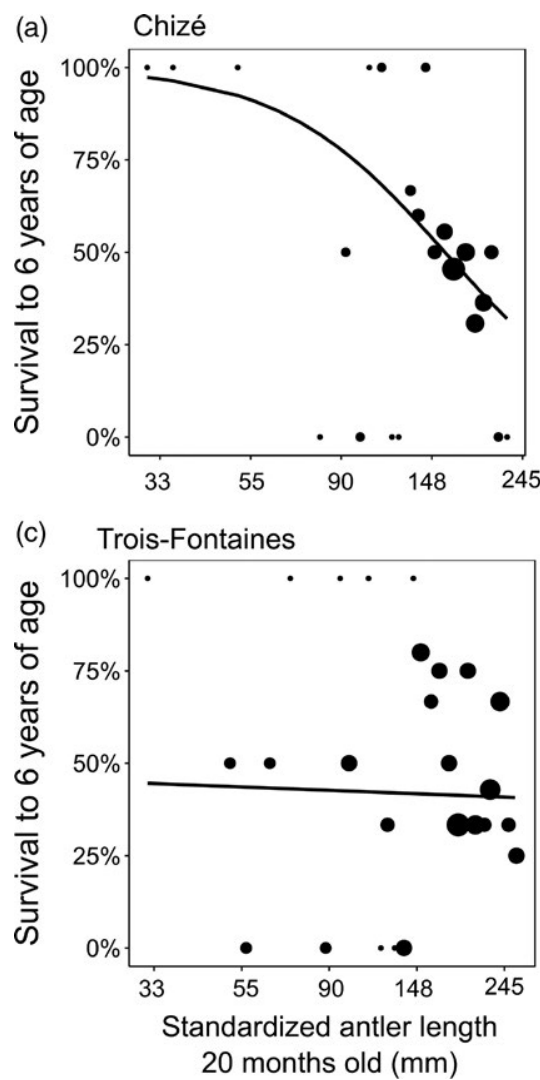

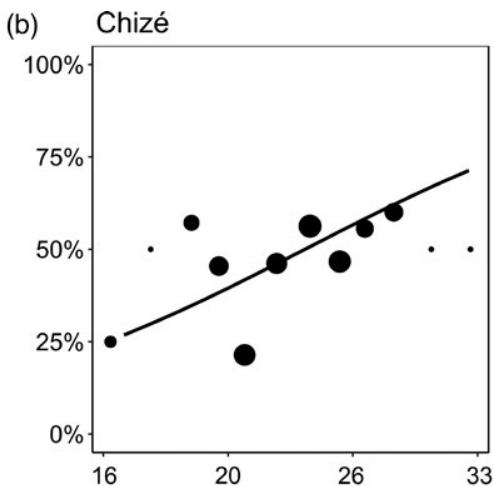

(d) Trois-Fontaines

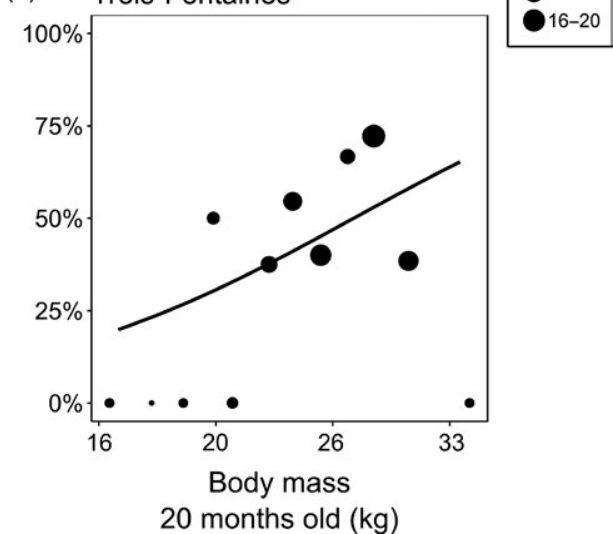


reproduction is positively associated with longevity in mammalian females (e.g. Descamps, Boutin, Berteaux, \& Gaillard, 2006), and our results suggest that this might also be the case in males. Yearlings that also grow relatively long antlers might suffer from more harassment by territorial males that are already established than those with smaller weapons (Wahlström, 1994), as suggested by the detected tendency for short-term survival costs.

A few recent studies have revealed that high levels of sexual competition can have long-term consequences in terms of age-specific decline in individual performance (Beirne, Delahay, \& Young, 2015; Lemaître et al., 2014). More generally, one promising avenue of research linking functional traits and population performance would be to investigate the dynamics of antler length very early in life and its impact on population growth. Our study highlights that growing large secondary sexual traits early in life might be a reliable indicator of individual performance, suggesting that variation in the expression of sexual traits within populations might directly influence population demography. Integral projection models (IPMs) provide a powerful tool to investigate this question (Coulson, 2012), but so far, IPMs have mostly focused on body mass or size as the focal trait (Vindenes \& Langangen, 2015) and most applications have been restricted to females. The recent development of two-sex models (Schindler et al., 2015) now offers a way to quantify how variation in the expression of sexual traits such as antler length influences the demography of a population, provided the required data (i.e. sex-specific relationships between demographic parameters [recruitment and survival] and antler length, father-offspring relationships and age-specific changes of antler length, pedigrees) will be available. As paternity analyses are becoming very common in wild vertebrates, we hope that our study will stimulate such studies that might reveal important insights on the role of sexual selection on population demography.

Finally, one striking paradox from our study is that the honest signal of individual performance conveyed by antler length is apparent in fawns when males do not compete for females. A possible explanation for the growth of long antlers in the pre-reproductive stage is the hormonal regulation of antler development that might be linked to physiological pathways involved in health and somatic maintenance. These constraints may have prevented natural selection from counterselecting the growth of substantial antlers in cervids well before they serve their purpose in male-male sexual contests (Sempéré \& Lacroix, 1982). Future work should test whether long antlers in the first years of life reflect the quality of the ejaculate and thus, possibly, male breeding success (Malo, Roldan, Garde, Soler, $\&$ Gomendio, 2005). Whether this signal is already present in fawn antlers is unknown (but note that young roe deer with long antlers also have large testes; Wahlström, 1994). This is the missing piece of the jigsaw for our understanding of the relationships between age-specific functional traits, health and demographic parameters.

\section{ACKNOWLEDGEMENTS}

Field operations were supported by grants from the Agence Nationale de la Recherche (ANR-15-CE32-0002-01), and performed within the framework of the LABEX ECOFECT (ANR-11-LABX-0048) of Universite de Lyon, within the program "Investissements d'Avenir" (ANR-11IDEX-0007) operated by the French National Research Agency (ANR). We thank all the ONCFS staff, in particular Claude Warnant and Gilles Capron, and the field volunteers for the organization of the roe deer captures. We warmly thank Dylan Childs and two anonymous referees for helpful and constructive comments that markedly improved our manuscript. The authors have declared that no conflict of interest exists. The land manager of both sites, Office National des Forêts (ONF), permitted the study of the populations (Partnership Convention ONCFSONF, dated 23-12-2005). All procedures were approved by the Ethical Committee of Lyon 1 University (project DR2014-09, 5 June 2014).

\section{AUTHORS' CONTRIBUTIONS}

J.F.L. and J.M.G. conceived the ideas and designed methodology; all authors collected the data on both study sites; and J.F.L., F.D. and J.M.G. analysed the data. J.F.L. wrote the first draft of the manuscript with input from J.M.G. and A.J.M.H., and all authors contributed critically to the drafts and gave final approval for publication.

\section{DATA ACCESSIBILITY}

All data have been deposited on Dryad Digital Repository: https:// doi.org/10.5061/dryad.vt169tn (Lemaître et al., 2018).

\section{ORCID}

Jean-François Lemaître (iD http://orcid.org/0000-0001-9898-2353

Louise Cheynel (iD http://orcid.org/0000-0003-2292-4143

\section{REFERENCES}

Adler, M. I., Telford, M., \& Bonduriansky, R. (2016). Phenotypes optimized for early-life reproduction exhibit faster somatic deterioration with age, revealing a latent cost of high condition. Journal of Evolutionary Biology, 29, 2436-2446. https://doi.org/10.1111/jeb.12968

Andersen, R., Duncan, P., \& Linnell, J. D. C. (1998). The European roe deer: The biology of success. Oslo, Norway: Scandinavian University Press.

Andersson, M. (1994). Sexual selection. Princeton, NJ: Princeton University Press.

Balbontín, J., \& Møller, A. P. (2015). Environmental conditions during early-life accelerate the rate of senescence in a short-lived passerine bird. Ecology, 94, 948-959. https://doi.org/10.1890/14-1274.1

Bartos, L., Bubenik, G. A., \& Kuzmova, E. (2012). Endocrine relationships between rank-related behaviour and antler growth in deer. Frontiers in Bioscience, E4, 1111-1126. https://doi.org/10.2741/e445

Bates, D., Mächler, M., Bolker, B. M., \& Walker, S. C. (2015). Fitting linear mixed-effects models using Ime4. Journal of Statistical Software, 67, 1-48.

Beirne, C., Delahay, R., \& Young, A. (2015). Sex differences in senescence: The role of intra-sexual competition in early adulthood. Proceedings of the Royal Society of London. Series B. Biological Sciences, 282, 20151086. https://doi.org/10.1098/rspb.2015.1086

Bergeron, P., Festa-Bianchet, M., von Hardenberg, A., \& Bassano, B. (2008). Heterogeneity in male horn growth and longevity in a 
highly sexually dimorphic ungulate. Oikos, 117, 77-82. https://doi. org/10.1111/j.2007.0030-1299.16158.x

Bleu, J., Gamelon, M., \& Saether, B.-E. (2016). Reproductive costs in terrestrial vertebrates: Insights from bird studies. Proceedings of the Royal Society of London. Series B. Biological Sciences, 283, 20152600. https://doi.org/10.1098/rspb.2015.2600

Bonduriansky, R. (2007). Sexual selection and allometry: A critical reappraisal of the evidence and ideas. Evolution, 61, 838-849. https://doi. org/10.1111/j.1558-5646.2007.00081.x

Bonenfant, C., Pelletier, F., Garel, M., \& Bergeron, P. (2008). Agedependent relationship between horn growth and survival in wild sheep. Journal of Animal Ecology, 78, 161-171.

Brommer, J. E., Ahola, K., \& Karstinen, T. (2005). The colour of fitness: Plumage coloration and lifetime reproductive success in the tawny owl. Proceedings of the Royal Society of London. Series B. Biological Sciences, 272, 935-940. https://doi.org/10.1098/rspb.2005.3052

Brooks, R. C., \& Garratt, M. G. (2017). Life history evolution, reproduction, and the origins of sex-dependent aging and longevity. Annals of the New York Academy of Sciences, 1389, 92-107. https://doi. org $/ 10.1111 /$ nyas.13302

Burnham, K. P., \& Anderson, D. R. (2002). Model Selection and multimodel inference: A practical information-theoretic approach. Berlin, Germany: Springer.

Chapman, D. I. (1975). Antler bones of contention. Mammal Review, 5, 121-172. https://doi.org/10.1111/j.1365-2907.1975.tb00194.x

Cody, M. L. (1966). A general theory of clutch size. Evolution, 20, 174184. https://doi.org/10.1111/j.1558-5646.1966.tb03353.x

Corlatti, L., Storch, I., Filli, F., \& Anderwald, P. (2017). Does selection on horn length of males and females differ in protected and hunted populations of a weakly dimorphic ungulate? Ecology and Evolution, 7, 3713-3723. https://doi.org/10.1002/ece3.2963

Coulson, T. (2012). Integral projections models, their construction and use in posing hypotheses in ecology. Oikos, 121, 1337-13650. https://doi.org/10.1111/j.1600-0706.2012.00035.x

Dantzer, B., \& Swanson, E. M. (2012). Mediation of vertebrate life histories via insulin-like growth factor-1. Biological Reviews, 87, 414-429. https://doi.org/10.1111/j.1469-185X.2011.00204.x

Descamps, S., Boutin, S., Berteaux, D., \& Gaillard, J. M. (2006). Best squirrels trade a long life for an early reproduction. Proceedings of the Royal Society of London. Series B. Biological Sciences, 273, 2369-2374. https://doi.org/10.1098/rspb.2006.3588

Ditchkoff, S. S., Spicer, L., Masters, R. E., \& Lochmiller, R. L. (2001). Concentrations of insulin-like growth factor-I in adult male whitetailed deer (Odocoileus virginianus): Associations with serum testosterone, morphometrics and age during and after the breeding season. Comparative biochemistry and Physiology, Part A, 129, 887-895. https://doi.org/10.1016/S1095-6433(01)00351-8

Douhard, F., Gaillard, J. M., Pellerin, M., Jacob, L., \& Lemaître, J.-F. (2017). The cost of growing large: Sex-specific costs of post-weaning growth on body mass senescence in a wild mammal. Oikos, 126, 1031-1041. https://doi.org/10.1111/oik.03799

Emlen, D. J. (2008). The evolution of animal weapons. Annual reviews of Ecology Evolution and Systematics, 39, 387-413. https://doi. org/10.1146/annurev.ecolsys.39.110707.173502

Foo, Y. Z., Nakagawa, N., Rhodes, G., \& Simmons, L. W. (2017). The effects of sex hormones on immune function: A meta-analysis. Biological Reviews, 92, 551-571. https://doi.org/10.1111/brv.12243

Gaillard, J. M., Delorme, D., Boutin, J. M., Van Laere, G., Boisaubert, B., \& Pradel, R. (1993a). Roe deer survival patterns - a comparative analysis of contrasting populations. Journal of Animal Ecology, 62, 778-791.

Gaillard, J. M., Delorme, D., Julien, J.-M., \& Tatin, D. (1993b). Timing and synchrony of births in roe deer. Journal of Mammalogy, 74, 738-744. https://doi.org/10.2307/1382296

Gaillard, J. M., Festa-Bianchet, M., Delorme, D., \& Jorgenson, J. (2000). Body mass and individual fitness in female ungulates: Bigger is not always better. Proceedings of the Royal Society of London. Series B. Biological Sciences, 267, 471-477. https://doi.org/10.1098/ rspb.2000.1024

Gaillard, J. M., Garratt, M., \& Lemaître, J.-F. (2017). Senescence in mammalian life-history traits. In R. P. Shefferson, O. Jones \& R. SalgueroGómez (Eds.), The evolution of senescence in the tree of life (pp. 126155). Cambridge, UK: Cambridge University Press.

Garratt, M., \& Brooks, R. C. (2012). Oxidative stress and conditiondependent sexual signals: More than just seeing red. Proceedings of the Royal Society of London. Series B. Biological Sciences, 279, 31213130. https://doi.org/10.1098/rspb.2012.0568

Geist, V. (1966). The evolutionary significance of mountain sheep horns. Evolution, 20, 558-566. https://doi.org/10.1111/j.1558-5646.1966. tb03386.x

Giraudeau, M., Friesen, C. R., Sudyka, J., Rolling, N., Whittington, C. M., Wilson, M. R., \& Olsson, M. (2016). Ageing and the cost of maintaining coloration in the Australian painted dragon. Biology Letters, 12, 20160077. https://doi.org/10.1098/rsbl.2016.0077

Goss, R. J. (1983). Deer antlers: Regeneration, function and evolution. New York, NY: Academic Press.

Hammers, M., Richardson, D. S., Burke, T., \& Komdeur, J. (2013). The impact of reproductive investment and early-life environmental conditions on senescence: Support for the disposable soma hypothesis. Journal of Evolutionary Biology, 26, 1999-2007. https://doi. org/10.1111/jeb.12204

Hewison, A. J. M., Gaillard, J. M., Angibault, J. M., Van Laere, G., \& Vincent, J. P. (2002). The influence of density on post-weaning growth in roe deer (Capreolus capreolus) fawns. Journal of Zoology, 257, 303-309. https://doi.org/10.1017/S0952836902000900

Hewison, A. J. M., Vincent, J. P., Angibault, J. M., Delorme, D., Van Laere, G., \& Gaillard, J. M. (1999). Tests of estimation of age from tooth wear on roe deer of known age: Variation within and among populations. Canadian Journal of Zoology, 77, 58-67. https://doi.org/10.1139/z98-183

Hooper, A. K., Lethonen, J., Schwanz, L. E., \& Bonduriansky, R. (2018). Sexual competition and the evolution of condition-dependent ageing. Evolution Letters, 2, 37-48. https://doi.org/10.1002/evl3.36

Jankowiak, L., Zyskowski, D., \& Wysocki, D. (2018). Age-specific reproduction and disposable soma in an urban population of Common Blackbirds Turdus merula. Ibis, 160, 130-144. https://doi. org/10.1111/ibi.12512

Jennions, M. D., Møller, A. P., \& Petrie, M. (2001). Sexually selected traits and adult survival: A meta-analysis. The Quarterly Review of Biology, 76, 3-36. https://doi.org/10.1086/393743

Kirkwood, T. B. (2017). The Disposable soma theory: Origins and evolution. In R. P. Shefferson, O. R. Jones \& R. Salguero-Gómez (Eds.), The evolution of senescence in the tree of life (pp. 23-39). Cambridge, UK: Cambridge University Press.

Kirkwood, T. B., \& Holliday, R. (1979). The evolution of aging and longevity. Proceedings of the Royal Society of London. Series B. Biological Sciences, 205, 531-546. https://doi.org/10.1098/rspb.1979.0083

Kirkwood, T. B., \& Rose, M. R. (1991). Evolution of senescence: Late survival sacrificed for reproduction. Philosophical Transactions of the Royal Society of London. Series B, Biological Sciences, 332, 15-24. https://doi.org/10.1098/rstb.1991.0028

Kotiaho, J. S. (2001). Costs of sexual traits: A mismatch between theoretical considerations and empirical evidence. Biological Reviews, 76, 365-376. https://doi.org/10.1017/S1464793101005711

Kuijper, B., Pen, I., \& Weissing, F. J. (2012). A guide to sexual selection theory. Annual Reviews of Ecology Evolution and Systematics, 43, 287311. https://doi.org/10.1146/annurev-ecolsys-110411-160245

Lee, W. S., Monaghan, P., \& Metcalfe, N. B. (2013). Experimental demonstration of the growth rate - lifespan trade-off. Proceedings of the Royal Society of London. Series B. Biological Sciences, 280, 20122370.

Lemaître, J. F., Berger, V., Bonenfant, C., Douhard, M., Gamelon, M., Plard, F., \& Gaillard, J. M. (2015). Early-late life trade-offs and the 
evolution of ageing in the wild. Proceedings of the Royal Society of London. Series B. Biological Sciences, 282, 20150209. https://doi. org/10.1098/rspb.2015.0209

Lemaître, J. F., Cheynel, L., Douhard, F., Bourgoin, G., Débias, F., Ferté, H., ... Gaillard, J.-M. (2018). Data from: The influence of early-life allocation to antlers on male performance during adulthood: Evidence from contrasted populations of a large herbivore. Dryad Digital Repository, https://doi.org/10.5061/dryad.vt169tn

Lemaître, J. F., \& Gaillard, J. M. (2017). Reproductive senescence: New perspectives in the wild. Biological Reviews, 92, 2182-2199. https:// doi.org/10.1111/brv.12328

Lemaître, J. F., Gaillard, J.-M., Pemberton, J. M., Clutton-Brock, T. H., \& Nussey, D. H. (2014). Early life expenditure in sexual competition is associated with increased reproductive senescence in male red deer. Proceedings of the Royal Society of London. Series B. Biological Sciences, 281, 20140792. https://doi.org/10.1098/ rspb.2014.0792

Loehr, J., Carey, J., Hoefs, M., Suhonen, J., \& Ylonen, H. (2007). Horn growth rate and longevity: Implications for natural and artificial selection in thinhorn sheep (Ovis dalli). Journal of Evolutionary Biology, 20, 818-828. https://doi.org/10.1111/j.1420-9101.2006.01272.x

Malo, A. F., Roldan, E. R. S., Garde, J., Soler, A. J., \& Gomendio, M. (2005). Antlers honestly advertise sperm production and quality. Proceedings of the Royal Society of London. Series B. Biological Sciences, 272, 149157. https://doi.org/10.1098/rspb.2004.2933

Metcalfe, N. B., \& Monaghan, P. (2003). Growth versus lifespan: Perspectives from evolutionary ecology. Experimental Gerontology, 38, 935-940. https://doi.org/10.1016/S0531-5565(03)00159-1

Pettorelli, N., Gaillard, J. M., Mysterud, A., Duncan, P., Stenseth, N. C., Delorme, D., ... Klein, F. (2006). Using a proxy of plant productivity (NDVI) to find key periods for animal performance: The case of roe deer. Oikos, 112, 565-572. https://doi.org/10.1111/j.0030-1299.2006.14447.x

Price, J., \& Allen, S. (2004). Exploring the mechanisms regulating regeneration of deer antlers. Philosophical Transactions of the Royal Society, Series B, 359, 809-822. https://doi.org/10.1098/rstb.2004.1471

$R$ Core Team. (2015). R: A language and environment for statistical computing. R Foundation for Statistical Computing, Vienna, Austria. https:// www.R-project.org/.

Robinson, M. R., Pilkington, J. G., Clutton-Brock, T. H., Pemberton, J. M., \& Kruuk, L. E. B. (2006). Live fast, die young: Trade-offs between fitness components and sexually antagonistic selection on weaponry in Soay sheep. Evolution, 60, 2168-2181. https://doi. org/10.1111/j.0014-3820.2006.tb01854.x

Rowe, L., \& Houle, D. (1996). The lek paradox and the capture of genetic variance by condition dependent traits. Proceedings of the Royal Society of London. Series B. Biological Sciences, 263, 1415-1421. https://doi.org/10.1098/rspb.1996.0207

Schams, D., Barth, D., Heinze-Mutz, E. M., Pflaum, G., \& Karg, H. (1992). Antler growth in roe deer: Effects of casting and correlations with growth hormone and insulin like growth factor I. In R. D. Brown (Ed.), The biology of deer (pp. 505-510). New York, NY: Springer-Verlag.

Schindler, S., Gaillard, J. M., Gruning, A., Neuhaus, P., Trail, L. W., Tuljapurkar, S., \& Coulson, T. (2015). Sex-specific demography and generalization of the Trivers-Willard theory. Nature, 526, 249-252. https://doi.org/10.1038/nature14968
Sempéré, A. J., \& Boissin, J. (1981). Relationship between antler development and plasma androgen concentrations in adult roe deer. Journal of Reproduction and Fertility, 62, 49-53. https://doi.org/10.1530/ jrf.0.0620049

Sempéré, A. J., \& Lacroix, A. (1982). Temporal and seasonal relationships between $\mathrm{LH}$, testosterone and antlers in fawn and adult male roe deer. Acta Endocrinologica, 99, 295-301.

Stearns, S. C. (1992). The evolution of life histories. Oxford, UK: Oxford University Press.

Tidière, M., Gaillard, J. M., Müller, D. W. H., Bingaman Lackey, L., Gimenez, O., Clauss, M., \& Lemaître, J. F. (2015). Does sexual selection shape sex differences in longevity and senescence patterns across vertebrates? A review and new insights from captive ruminants. Evolution, 69, 3123-3140. https://doi.org/10.1111/ evo.12801

Toïgo, C., Gaillard, J. M., \& Loison, A. (2013). Alpine ibex males grow large horns at no survival cost for most of their lifetime. Oecologia, 173, 1261-1269. https://doi.org/10.1007/s00442-013-2700-1

Ulm, K., \& Cox, C. (1989). On the estimation of the threshold values. Biometrics, 45, 1324-1328.

Vanpé, C., Gaillard, J. M., Kjellander, P., Delorme, D., \& Hewison, A. J. M. (2010). Assessing the intensity of sexual selection on male body mass and antler length in roe deer Capreolus capreolus: Is bigger better in a weakly dimorphic species? Oikos, 119, 1484-1492. https:// doi.org/10.1111/j.1600-0706.2010.18312.x

Vanpé, C., Gaillard, J. M., Kjellander, P., Mysterud, A., Magnien, P., Delorme, D., ... Hewison, A. J. M. (2007). Antler size provides an honest signal of male phenotypic quality in roe deer. The American Naturalist, 169, 481-493. https://doi.org/10.1086/512046

Vanpé, C., Gaillard, J. M., Morellet, N., Kjellander, P., Liberg, O., Delorme, D., \& Hewison, A. J. M. (2009). Age-specific variation in male breeding success of a territorial ungulate species, the European roe deer. Journal of Mammalogy, 90, 661-665. https://doi. org/10.1644/08-MAMM-A-137R.1

Vindenes, Y., \& Langangen, Ø. (2015). Individual heterogeneity in life histories and eco-evolutionary dynamics. Ecology Letters, 18, 417-732. https://doi.org/10.1111/ele.12421

Wahlström, L. K. (1994). The significance of male-male aggression for yearling dispersal in roe deer (Capreolus capreolus). Behavioral Ecology and Sociobiology, 35, 409-412. 